\title{
Some artifical isotopes in Yenisei river biogeocynosis: contents, speciation, pollutant flow
}

M.Yu. Kropacheva, M.S. Melgunov, A.V. Chuguevsky, K.A. MeZina AND I.V. MAKarova

Sobolev Institute of Geology and Mineralogy SB RAS,

630090 Novosibirsk, Russi (marya@igm.nsc.ru)

The Krasnoyarsk Mining and Chemical Combine (KMCC) has affected the Yenisei River floodplain for more than 50 years. In the past, the operation of two direct-flow reactors and one closed-loop reactor had a significant influence; traces of this influence are observed along the entire course of the river up to the Kara Sea [1]. After stopping the KMCC reactor facilities, the impact sharply decreased [2], but did not disappear completely [3]. In particular, a large number of long-lived isotopes have remained deposited in river floodplains sediments [4].

Previous studies of the impact have been conducted quite widely and covered floodplain sediments, water and aquatic biota $[4,5]$. Our research aimed to study the behavior of artificial isotopes $\left({ }^{137} \mathrm{Cs},{ }^{90} \mathrm{Sr},{ }^{60} \mathrm{Co},{ }^{152,154} \mathrm{Eu}\right)$ in the system "floodplain soil - plant's rhizosphere - roots of plant - aerial parts of plant". From 2004 to 2016 the artificial isotopes contents stay at a sufficiently high level in all components of the system in the KMCC near impact zone, which confirms the ongoing impact on floodplain biogeocynosis by KMCC. Sufficiently noticeable isotope contents are also observed in the middle impact zone: isotope contents in some system components increase with the distance from the KMCC. The artificial isotopes speciation in the substrate significantly depend on the river hydrological regime and on the presence of conditions favorable for deposition of suspended material, on which isotopes are sorbed to one degree or another. The degree of ${ }^{137} \mathrm{Cs}$ removal from the system components was evaluated using the example of the Atamanovskaya spit as a model site. According to preliminary estimates, ${ }^{137} \mathrm{Cs}$ removal from various system components may reach $\mathrm{MBq}$ per season. In order to obtain more accurate estimates, fiels and laboratory experiments are necessary.

The work is done on state assignment of IGM SB RAS and is partly support by RFBR Grant 18-05-00953.

[1] Vakulovsky et al. (1995) J. Environ. Radioact. 29(3), 225-236. [2] Nosov (1996) At. Energy 81(3), 670-674. [3] Bolsunovsky \& Melgunov (2014) J. Geosci. Environ. Prot. 2, 153-158. [4] Linnik et al. (2014) J. Geochemical Explor. 142, 60-68. [5] Zotina et al. (2019) J. Environ. Radioact. 208-209, 106028 . 